\title{
The Pharmacological Effects of Fagonia Cretica Linn Ethanolic Extract on Isolated Rabbit Intestine
}

\author{
Aimun AE. Ahmed ${ }^{* 1}$, Tasnim O. Elsammani ${ }^{2}$, Mawahib E. H. Elfeil ${ }^{2}$, Samrin K. N. Ahmed ${ }^{2}$ \\ ${ }^{*}$ Department of Pharmacology, Faculty of Pharmacy, Omdurman Islamic University, Sudan \\ 2 Department of Pharmacology, Faculty of Pharmacy, International University of Africa, Sudan \\ *Corresponding author E-mail: Aimun725@hotmail.com
}

\begin{abstract}
The aim of this study was to verify the pharmacological effect(s) of the Fagonia cretica linn (Zygophyllaceae) ethanolic extract and to determine the mechanism(s) underlay its action using isolated rabbit intestine.

The cumulative dose-response curves of the Fagonia cretica extract and standard adrenaline were constructed using different doses ranged $\left(10^{-3}-10^{2} \mu \mathrm{g} / \mathrm{ml}\right)$, and $\left(10^{-9}-10^{-5} \mathrm{M}\right)$ alone, and in the presence of a single dose of a blocker, then the values of $\mathrm{EC}_{50}, \mathrm{E}_{\max }$ and $\mathrm{pA}_{2}$ were determined as mean \pm S.E.M, and compared statistically. The adrenergic non-selective blockers, phentolamine and propranolol in concentrations of $\left(10^{-8}\right.$ and $\left.10^{-5} \mathrm{M}\right)$ were used to elucidate the exact mechanism mediating the relaxant effect of the ethanolic extract of Fagonia cretica linn.

Results revealed that Fagonia cretica exhibited a dose-dependent relaxant activity on rabbit intestine similar to that produced by standard adrenaline with, $\mathrm{E}_{\max }=[56.4 \pm 7.5],[7.2 \pm 4.3]$ and $\mathrm{EC}_{50}=[0.12 \pm 0.27],[9.85 \pm 1.6] \mathrm{x} 10^{-6}$ respectively. This effect was mediated through both $\alpha$ and $\beta$ adrenoceptors, whilst there is no participation of direct muscle relaxant in mediating the relaxant effect of the plant extract.

More detailed studies were recommended to deeply investigate and confirm these findings by using other techniques.
\end{abstract}

Keywords: Fagonia cretica linn, umm shawaika, isolated rabbit intestine, relaxant activity, ethanolic extract, adrenaline.

\section{Introduction}

Fagonia cretica linn (Zygophyllaceae), Known locally in Sudan as Umm Shok, Umm Shawaika and Sholib [1]. A small spiny under shrub with stiff, different prostrate branches [2].Distributed in Mexico, south western USA, Chile, Peru, Africa, Asia and the southern Europe [3]. The plant is found in the west, northern and central Sudan [1].

Fagonia cretica linn used traditionally as astringent, prophylactic against smallpox [4], anti-inflammatory and in the treatment of blood vascular diseases [5], fever, thirst, vomiting, dysentery, asthma, urinary discharges, liver problems, typhoid, toothache, stomach problems and skin diseases.

The boiled aqueous plant residue is used to induce abortion and used as a topical paste for tumors and swellings of the neck. An aqueous plant decoction is a popular remedy for cancer in the indigenous system of medicine [4]. The plant leaves are used as antifertility [6]. The macerated whole plant is used as antispasmodic, whilst the powdered fruits mixtures with sour milk are taken instantly as antipurgative [1].

Fagonia cretica chemical components include amino acids such as alanine, glycine, leucine, arginine isoleucine, lysine, phenylalanine, proline, tyrosine and valline [2]. The alkaloids Harmine, Harman, triterpinoid saponins, bisdesmosidic saponins, sapogenins and oleanolic acid. Triterpinoids sterols, alcohol (cerylalcohol and n-tri-contanol, flavanol glycosids) and fatty acids [1].

Although literature revealed the extensive traditional use of Fagonia Cretica, its pharmacological profile remains controversial. This study was carried out to investigate the Pharmacological effects of Fagonia cretica Linn ethanolic extract on isolated rabbit intestine and to elucidate the mechanism(s) of action of extract using standard drugs. 


\section{Materials and methods}

\subsection{Standard drugs}

The standard drugs such as; Propranolol hydrochloride, Phentolamine hydrochloride and adrenaline were obtained from SIGMA-ALDRICH (China).

\subsection{Plant material}

\section{A. Plant material collection and identification}

The whole plant Fagonia cretica except the aerial parts was collected from uncultivated and west areas of Shandi town near to faculty of medical and health sciences in January- February 2011 authenticated by herbarian staff, Department of botany Sudanese national centre for research in Sudan. A voucher specimen was deposited there for future references.

\section{B.Extraction method}

Extraction was carried out according to the method described by Harborne [7]; $2000 \mathrm{~g}$ of plant (Part) coarse dried powder sample was extracted with $80 \%$ ethanol using shaker apparatus for five days. The plant was washed with distilled water and allowed to dry before ethanolic extraction was carried out. Extraction was carried till the color of the solvent returned colorless. Solvents were evaporated under reduced pressure using rotary evaporator apparatus. The extract was allowed to completely dry on air. The coarse powder plant yielded $7 \%$ ethanolic extract.

\subsection{Ethical consideration and animal housing}

Young healthy domestic rabbits were obtained from local market weighting (1-3 kg), after ethical approval had been obtained from institutional animal ethical committee of the faculty of pharmacy IUA under permission number: IUA, IAEC/ Exp. Ph. 013/01.

The rabbits were fed grass, carrots, carrots tops and water ad libitum and were maintain at standard laboratory conditions for adaptation before experiments.

\subsection{Experiment setup}

The Rabbit was fasted overnight and in the morning was killed by dislocating the neck and exanguinated the animal. The abdomen was opened and suitable length of the rabbit jejunum was isolated after precise location determination and transferred to beaker contains tyrode solution (composition: $40 \mathrm{~g}$ of $\mathrm{NaCl}, 5 \mathrm{~g} \mathrm{NaHCO}, 5 \mathrm{~g} \mathrm{D}-\mathrm{Glucose}, 0.25 \mathrm{~g}$ $\mathrm{NaH}_{2} \mathrm{PO}_{4}, 1 \mathrm{~g} \mathrm{KCI}$ and $0.5 \mathrm{~g} \mathrm{MgCI}_{2}$ to 4.7 liter distilled water and $1.32 \mathrm{~g}$ of $\mathrm{CaCI}_{2} .2 \mathrm{H}_{2} \mathrm{O}$ in $300 \mathrm{ml}$ distilled water) and act as reservoir. Then for every experiment, 1-1.5 inch was cut, cleaned from attached connective tissues and food-if present- by passing tyrode solution using $5 \mathrm{ml}$ syringe. Then a thread was attached to both top (fixed to the recording lever) and bottom (fixed to the tissue holder). Then the tissue was left 30 minutes. $37^{\circ} \mathrm{C}$ which maintained by thermostat and the Tyrode kreb's solution was changed every 10 minutes.

The preparation was balanced using a piece of plasticine weight $1 \mathrm{~g}$ to constant baseline of spontaneous activity, and then the tested material was added in a fixed cumulative dose cycle to obtain uniform readings.

The recording traces of six experiments each were measured using ruler after calibration of the whole responses using different standard weights and it was found that every $1 \mathrm{gm}=1 \mathrm{~cm}$. The baseline (normal) was set as zero while other responses were correlated to it using the excel sheet and equation $\left(\left(=D_{i} / D_{b}\right) * 100\right) D_{b}=$ response of the baseline in cm while $\mathrm{D}_{\mathrm{i}}=$ response of the given dose in $\mathrm{cm}$ ), that furtherly used to draw the dose-response curve and calculate the desired pharmacological parameters.

\section{A.Screening for biological activity}

The responses of Fagonia cretica linn ethanolic extract and standard adrenaline were obtained by addition of the six doses ranged $\left(10^{-4}-10^{2} \mu \mathrm{g} / \mathrm{ml}\right)$ and $\left(10^{-9}-10^{-5} \mathrm{M}\right)$ final organ bath concentration of each, respectively in cumulative manner with contact time 1 minute for each dose (this step was repeated 6 times).

\section{B.Mechanism of action determination}

For adrenergic activity both non-selective $\beta$-blocker (propranolol) and non-selective $\alpha$-blocker (phentolamine) in two different concentrations low $\left[10^{-8} \mathrm{M}\right]$ and high $\left[10^{-5} \mathrm{M}\right]$ were used to competitively reverse the relaxant activity of the extract and the standard adrenaline.

For direct muscle relaxant activity that thought to be participated in mediating the above mentioned relaxant activity of Fagonia cretica linn ethanolic extract, two doses from the both adrenoceptor antagonists (propranolol and phentolamine) low $\left[10^{-8} \mathrm{M}\right]$ and high $\left[10^{-5} \mathrm{M}\right]$ were added at the same time and the cumulative dose-response curve of the extract and standard adrenaline were constructed and compared. 


\section{$2.5 \mathbf{p A}_{2}$-value calculation}

$\mathrm{pA}_{2}$-value for the antagonist (propranolol, phentolamine or both) with all agonist (adrenaline, plant extract) were calculated using the Schill's equation:

$$
\mathrm{pA}_{2}=\mathrm{pA}_{\mathrm{x}}+\log (\mathrm{x}-1)
$$

$\mathrm{pA}_{\mathrm{x}}=-\log$ of antagonist concentration.

The $\mathrm{pD}_{2}$ was calculated for the agonist with and without antagonist from the in vitro $\mathrm{EC}_{50}$ results then applied to the above mentioned equation.

$$
\mathrm{D}_{2}=-\log \left(\mathrm{EC}_{50}\right)
$$

$\mathrm{x}=\mid \mathrm{pD}_{2}$ agonist alone- $\mathrm{pD}_{2}$ agonist with antagonist $\mid$

\subsection{Statistical analysis}

Statistical evaluation was performed with Prism 5.0 computer program. Data were analyzed by means of the two-tailed unpaired t-test to compare the mean differences for various results. The differences were considered to be significant at $\mathrm{P} \leq 0.05$.

\section{Results}

\subsection{Preliminary effect of Fagonia cretica linn on isolated rabbit intestine}

Fagonia cretica Linn ethanolic extract produced dose-dependent relaxant effect on isolated rabbit jejunum similar to that produced by standard adrenaline in a dose range of $10^{-4} \mathrm{M}-10^{-9} \mathrm{M}$ (Fig. 1).

$1 \mathrm{~A}$

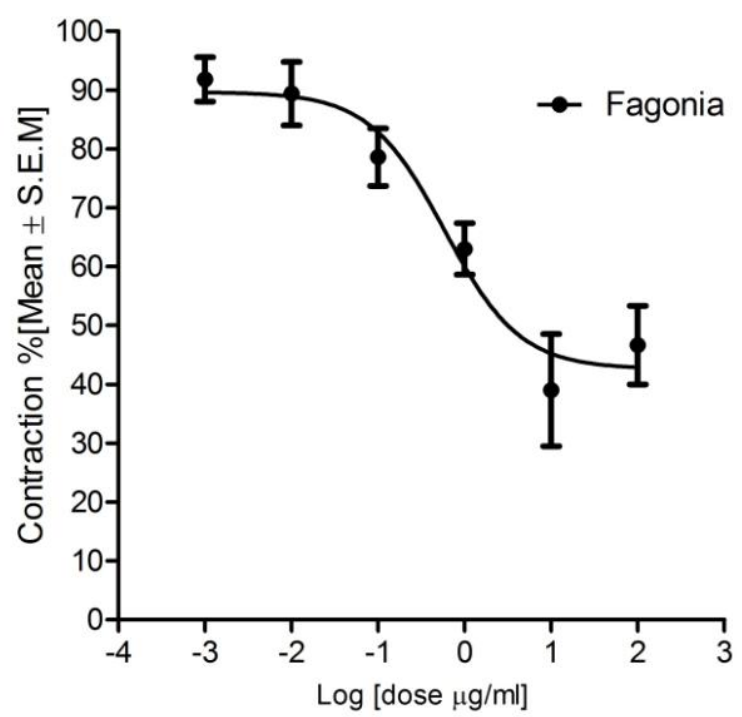

$1 B$

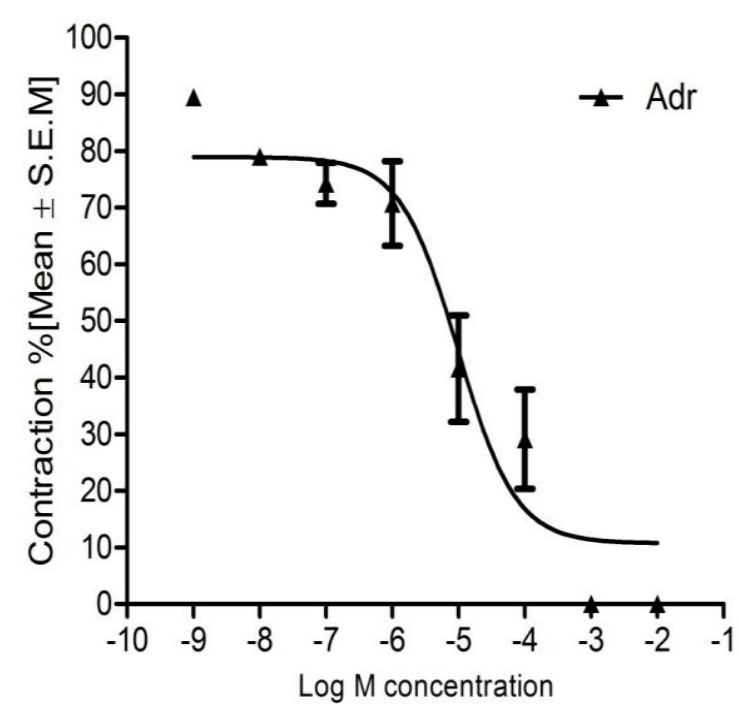

Fig. 1: Cumulative dose-response curve of F. cretica linn ethanolic extract (1A) and the standard Adrenaline (1B) on isolated rabbit intestine. Values presented are means of 5-7 observations, vertical bar denote standard errors of the mean (S.E.M).

The $\mathrm{EC}_{50}$ which indicates potency and $\mathrm{E}_{\max }$ which indicate efficacy for Fagonia cretica linn ethanolic extract and the standard adrenaline as mean \pm S.E.M in the same time their statistical comparison level of significant can be seen elearly in table 1 .

\subsection{Mechanism of action determination results}

\section{A. $\beta$-Adrenoceptors effects}

Non-selective $\beta$-blocker (Propranalol) in low dose $\left(10^{-8} \mathrm{M}\right)$ and in high dose $\left(10^{-5} \mathrm{M}\right)$ shift the dose-response curve of ethanolic extract of Fagonia cretica linn to the right in dose-dependent fashion similar to adrenaline in isolated rabbit intestine, see Fig. 2,3 and related table 2. 
Table 1: Summary of the main pharmacological parameters $\mathrm{EC}_{50}$ and $\mathrm{E}_{\max }$ of $\mathrm{F}$. cretica linn ethanolic extract and standard adrenaline presented as mean \pm S.E.M in both conditions.

\begin{tabular}{ccc}
\hline Tested Substance & $\mathrm{EC}_{50}$ & $\mathrm{E}_{\max }$ \\
& {$[$ Mean \pm S.E.M $]$} & {$[$ Mean \pm S.E.M $]$} \\
\hline F. Cretica EE $(\mu \mathrm{g} / \mathrm{ml})$ & {$[0.12 \pm 0.27]$} & $56.4 \pm 7.5$ \\
Adrenaline $(\mathrm{M})$ & {$[9.85 \pm 1.6] \times 10^{-6}$} & $7.2 \pm 4.3$ \\
P-value & 0.036 & 0.01 \\
\hline
\end{tabular}

$\mathrm{E}_{\max } ;$ maximum relaxing effect, $\mathrm{EC}_{50}$ : concentration producing $50 \%$ of the maximum relaxing effect, S.E.M: standard errors of the mean, $\mathrm{P} \leq 0.05$ : statistically significant.

2A

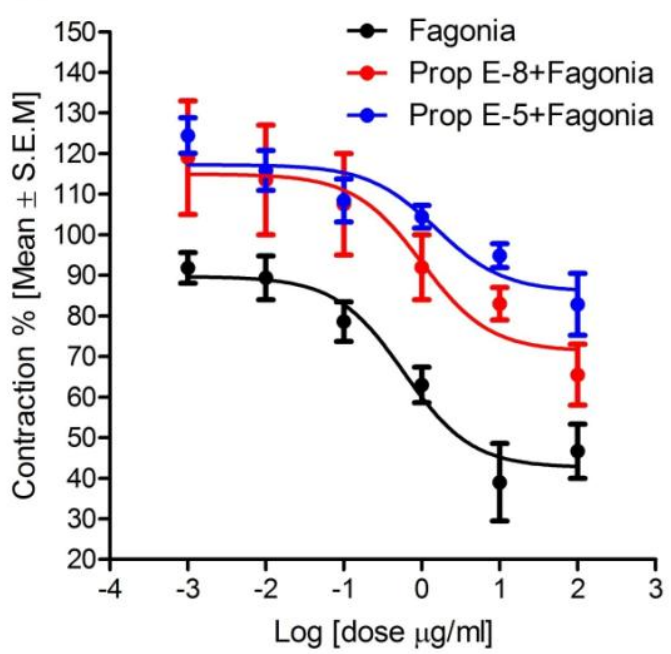

2B

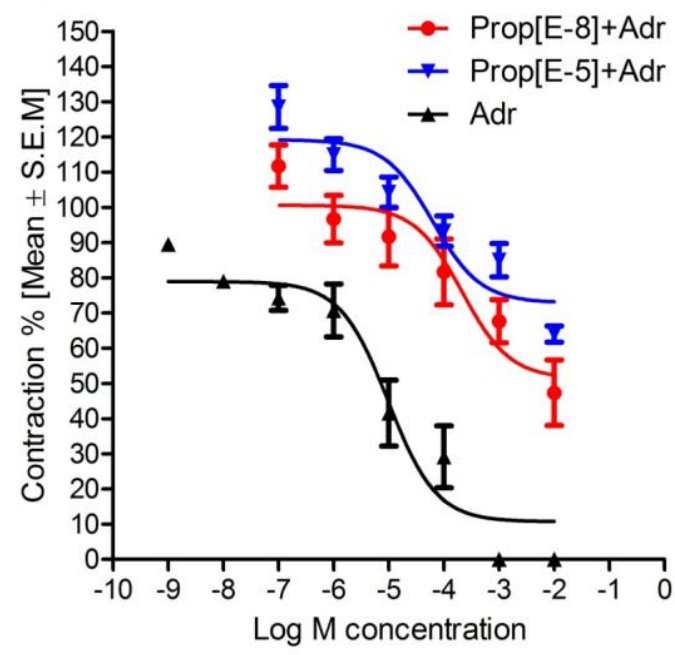

Fig. 2: Cumulative dose-response curve of the effect of non-selective $\beta$-blockers (Propranolol) in a dose of $\left[10^{-8} \mathrm{M}\right.$ and $\left.10^{-5} \mathrm{M}\right]$ on relaxant activity of F. cretica linn ethanolic extract $(\mathbf{2 A})$ and the standard adrenaline (2B) on isolated rabbit intestine. Values presented are means of 5-7 observations, vertical bar denote standard errors of the mean (S.E.M).

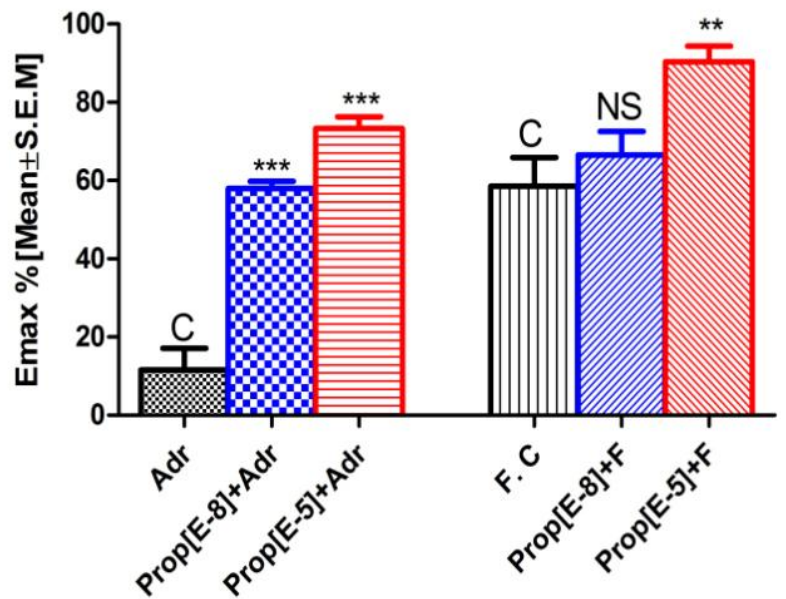

Fig. 3: $\mathrm{E}_{\max }$ values for F. cretica linn ethanolic extract and standard Adrenaline with propranolol in concentration of $10^{-5} \mathrm{M}$ and $10^{-8} \mathrm{M}$ and without propranolol. **: $\mathrm{P}<0.01$, ***: $\mathrm{P}<0.001$, NS: not significant. Adr: standard Adrenaline, prop: Propranolol, F. C: Fagonia cretica Linn ethanolic extract.Results expressed are a mean of 6 independent experiments \pm SEM.

Table 2: $\mathrm{pA}_{2}$ values of the action of Propranolol in a dose of $\left[10^{-8} \mathrm{M}\right.$ and $\left.10^{-5} \mathrm{M}\right]$ on relaxant activity of F. cretica ethanolic extract and the standard Adrenaline on isolated rabbit intestine.

\begin{tabular}{ccc}
\hline Tested Sub & $\mathrm{pA}_{2}$ & P-value \\
& [Mean \pm S.EM], N=6 & Control \\
Adr+prop $10^{-8}$ & $4.5 \pm 0.5$ & 0.003 \\
F. C + prop $10^{-8}$ & $1.4 \pm 0.2$ & Control \\
Adr+prop $10^{-5}$ & $5.1 \pm 0.2$ & 0.001 \\
F. C + prop $10^{-5}$ & $1.8 \pm 0.3$ & 0.01 \\
\hline
\end{tabular}


Adr: standard Adrenaline, prop: Propranolol, F. C: Fagonia cretica Linn ethanolic extract. pA 2 : negative logarithm of the antagonist concentration that reduces an agonist effect to $\mathrm{E}_{\max } / 2$. The results considered significant when $\mathrm{P}$-value $\leq$ 0.05 .

The Mean \pm S.E.M. of $E_{\max }$ values that indicate efficacy of both Fagonia cretica linn ethanolic extract and standard Adrenaline were calculated with and without antagonist and presented in a one a bar chart in Fig. 3.

\section{B. $\alpha$-Adrenoceptors effect}

The non-selective $\alpha$-blocker (phentolamine) shift both dose- response curves of Fagonia cretica linn ethanolic extract and standard Adrenaline to the right in a dose-dependent manner calculated as $\mathrm{pA}_{2}$ value see Fig. 4,5 and related table 3.
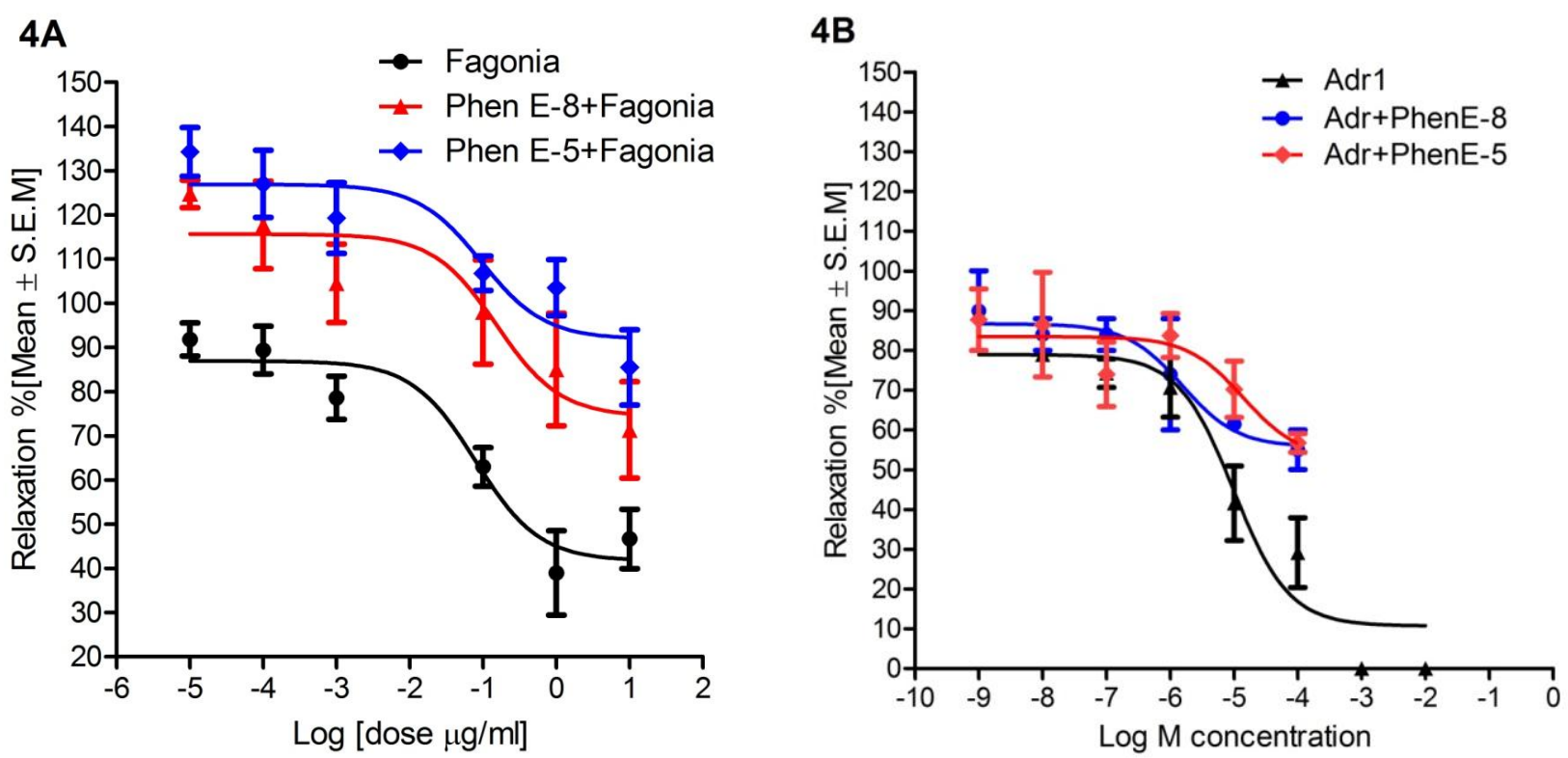

Fig. 4: Cumulative dose-response curve of the effect of phetolamine in a dose of $\left[10^{-8}\right.$ and $\left.10^{-5} \mathrm{M}\right]$ on relaxant activity of $\mathrm{F}$. cretica ethanolic extract (4A) and the standard Adrenaline (4B) on isolated rabbit intestine. Values presented are means of 4-6 observations, vertical bar denote standard errors of the mean (S.E.M).

The calculated $\mathrm{pA}_{2}$ values that indicate affinity of both Fagonia cretica linn ethanolic extract and standard adrenaline with Propranolol (antagonist) in a dose of $\left[10^{-8} \mathrm{M}\right.$ and $\left.10^{-5} \mathrm{M}\right]$ for at least six repeated measures were showed in a tabular form (Table 3).

Table 3: $\mathrm{pA}_{2}$ values of the action of Phentolamine in a dose of $\left[10^{-8}\right.$ and $\left.10^{-5} \mathrm{M}\right]$ on relaxant activity of F. cretica ethanolic extract and the standard Adrenaline on isolated rabbit intestine (presented as Mean \pm S.E.M in both conditions).

\begin{tabular}{ccc}
\hline Tested Subs & $\begin{array}{c}\mathrm{pA}_{2} \\
\text { [Mean } \pm \text { S.E.M]N=6 }\end{array}$ & Control \\
Adr+Phen $10^{-8}$ & $4.4 \pm 0.6$ & 0.008 \\
F. C + Phen $10^{-8}$ & $0.7 \pm 0.3$ & Control \\
Adr+ Phen $10^{-5}$ & $5.6 \pm 1.0$ & 0.04 \\
F. C + Phen $10^{-5}$ & $1.5 \pm 0.2$ & \\
\hline
\end{tabular}

Adr: standard Adrenaline, Phen: Phentolamine, F. C: Fagonia cretica Linn ethanolic extract. $\mathrm{pA}_{2}$ : negative logarithm of the antagonist concentration that reduces an agonist effect to $\mathrm{E}_{\max } / 2$. The results considered significant when $\mathrm{P}$-value $\leq$ 0.05 .

The Mean \pm S.E.M. of $E_{\max }$ values that indicate efficacy of both Fagonia cretica linn ethanolic extract and standard Adrenaline were calculated with and without antagonist and presented in a one bar chart in Fig. 5. 


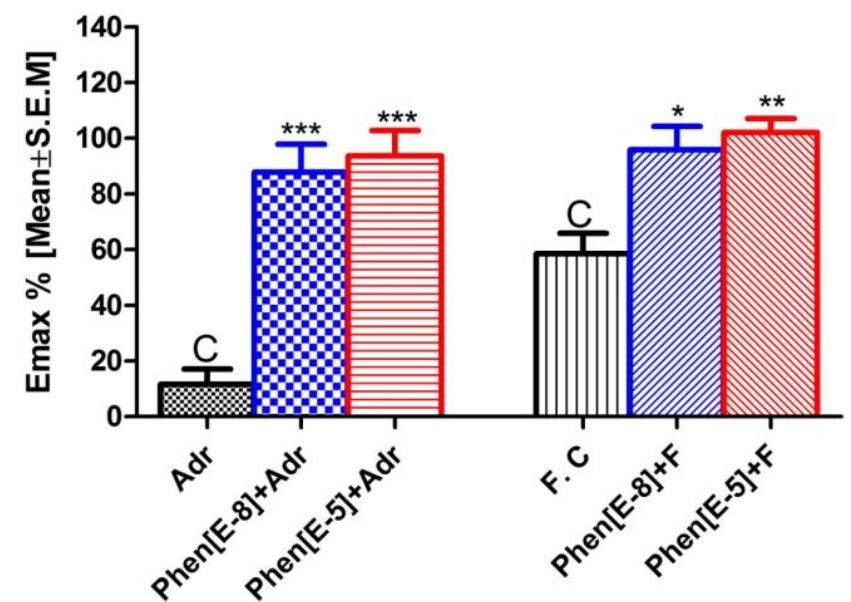

Fig. 5: $\mathrm{E}_{\max }$ values for F. cretica linn ethanolic extract and standard Adrenaline with phentolamine in concentration of $10^{-5} \mathrm{M}$ and $10^{-8} \mathrm{M}$ and without. *: $\mathrm{P}<0.05$, **: $\mathrm{P}<0.01$, ***: $\mathrm{P}<0.001$. Adr: standard Adrenaline, Phen: Phentolamine, F. C: Fagonia cretica Linn ethanolic extract.Results expressed are a mean of 6 independent experiments \pm SEM.

\section{Both $\alpha$ and $\beta$-adrenoceptors effects}

Combination of both non-selective adrenoceptors blockers (Propranolol and Phetolamine) in dose of $\left[10^{-8}\right.$ and $\left.10^{-5} \mathrm{M}\right]$ reverse the relaxant effect of Fagonia cretica ethanolic extract as with standard Adrenaline on isolated rabbit intestine as shown in Fig. 6,7 and table 4.
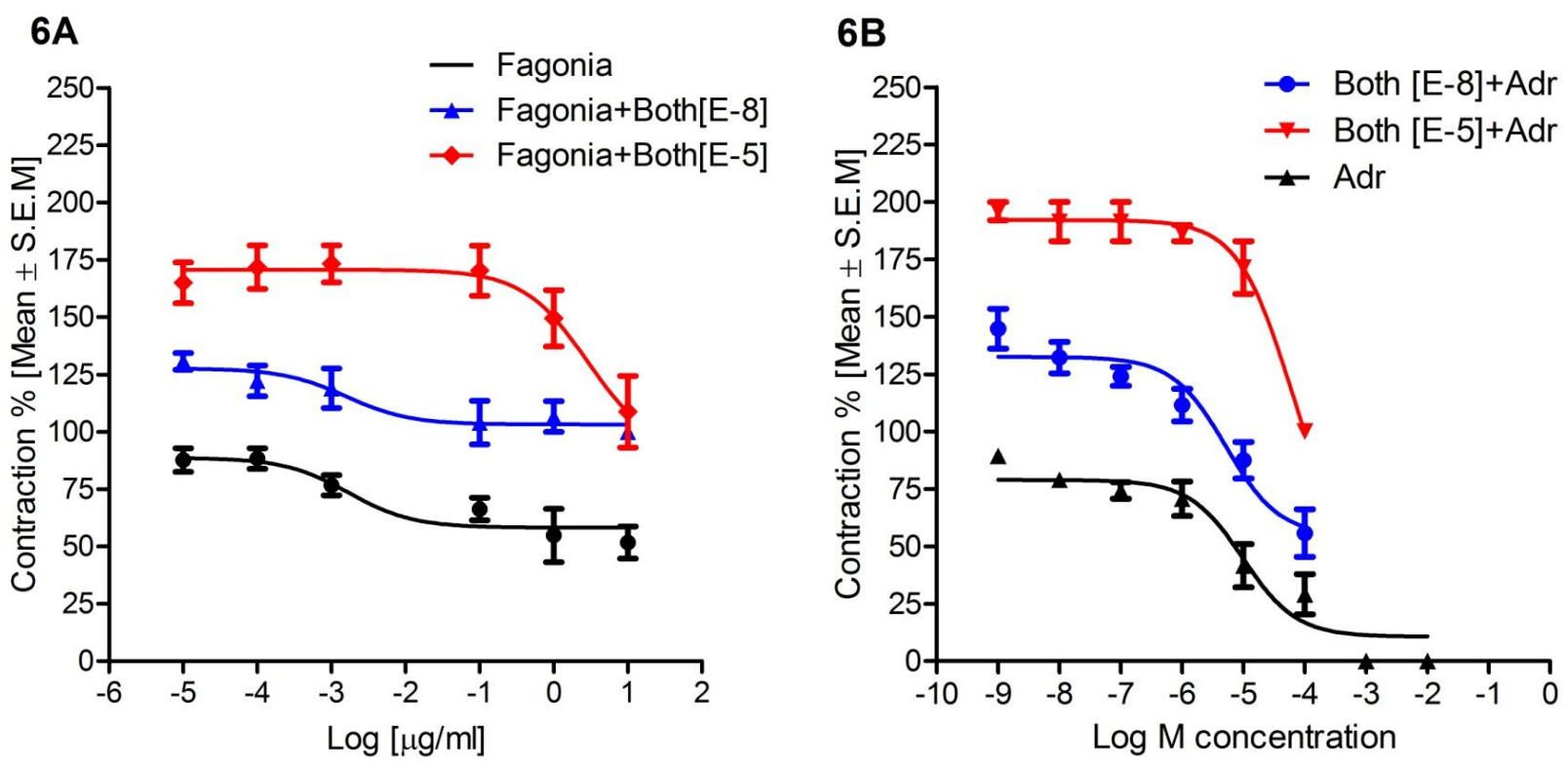

Fig. 6: Cumulative dose-response curve of the effect of both (Propranolol and Phetolamine) in a dose of $\left[10^{-8}\right.$ and $\left.10^{-5} \mathrm{M}\right]$ on relaxant activity of F. cretica ethanolic extract $(\mathbf{6 A})$ and the standard adrenaline $(\mathbf{6 B})$ on isolated rabbit intestine. Values presented are means of 2-5 observations, vertical bar denote standard errors of the mean (S.E.M).

Mean \pm S.E.M. of $\mathrm{E}_{\max }$ values which represent efficacy of both Fagonia cretica linn ethanolic extract and standard Adrenaline were calculated with and without both blockers (Phentolamine and Propranolol) at concentration $10^{-5} \mathrm{M}$ and $10^{-8} \mathrm{M}$ and presented in a one a bar chart in Fig. 7. 


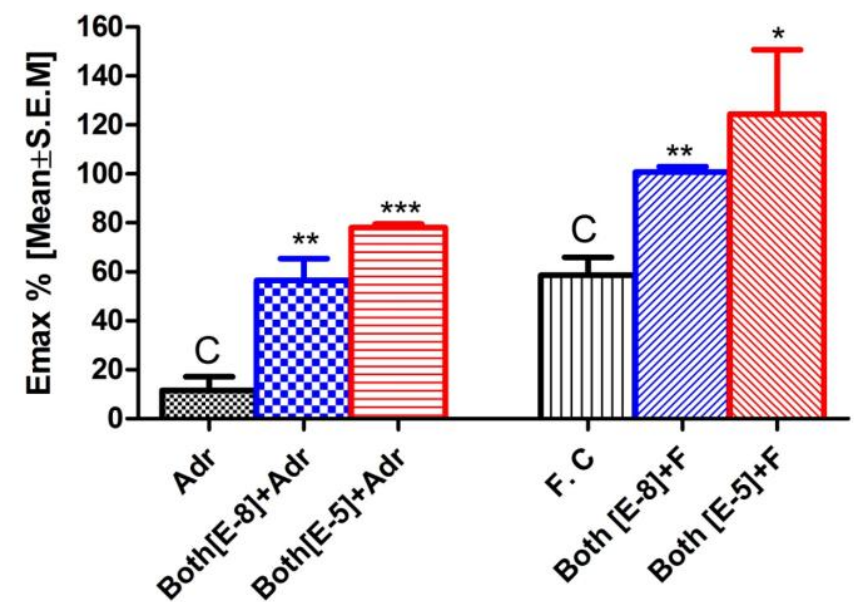

Fig. 7: $\mathrm{E}_{\max }$ values for F. cretica linn ethanolic extract and standard Adrenaline with both blockers phentolamine and propranolol in concentration of $10^{-5} \mathrm{M}$ and $10^{-8} \mathrm{M}$ and without them. *: $\mathrm{P}<0.05$, $* *: \mathrm{P}<0.01$, ***: $\mathrm{P}<0.001$. Adr: standard Adrenaline, both: both blockers phentolamine and propranolol at the same time, F. C: Fagonia cretica Linn ethanolic extract.Results expressed are a mean of 6 independent experiments \pm SEM.

The calculated $\mathrm{pA}_{2}$ values that indicate affinity of both Fagonia cretica linn ethanolic extract and standard adrenaline with Phentolamine and propranolol in a dose of $\left[10^{-8} \mathrm{M}\right.$ and $\left.10^{-5} \mathrm{M}\right]$ for at least six repeated measures were showed in a tabular form (Table 4).

Table 4: $\mathrm{pA}_{2}$ values of the action of both (Phentolamine and Propranolol) in a dose of $\left[10^{-8}\right.$ and $\left.10^{-5} \mathrm{M}\right]$ on relaxant activity of $\mathrm{F}$. cretica ethanolic extract and the standard Adrenaline on isolated rabbit intestine.

\begin{tabular}{ccc}
\hline Tested Subs & $\mathrm{pA}_{2}$ & P-value \\
[Mean \pm S.E.M], N=6 & Control \\
Adr +both $10^{-8}$ & $4.5 \pm 0.04$ & 0.006 \\
F. C + both $10^{-8}$ & $1.6 \pm 0.2$ & Control \\
Adr + both $10^{-5}$ & $3.6 \pm 0.1$ & 0.021 \\
F. C + both $10^{-5}$ & $2.0 \pm 0.2$ & \\
\hline
\end{tabular}

Adr: standard Adrenaline, both: both antagonist propranolol and phentolamine, F.C: Fagonia cretica Linn ethanolic extract. $\mathrm{pA}_{2}$ : negative logarithm of the antagonist concentration that reduces an agonist effect to $\mathrm{E}_{\max } / 2$, subs: substances. The results considered significant when $\mathrm{P}$-value $\leq 0.05$.

\section{Discussion}

The current study revealed that Fagonia cretica exhibited a dose-dependent relaxant activity on rabbit jejunum similar to that produced by standard adrenaline. Moreover, the extract appear less affinity to adrenoceptors than Adrenaline ( $\mathrm{p}=$ 0.04 ), whilst the extract efficacy was approximately less than half of that of adrenaline $(\mathrm{p}=0.01)$, indicating that, Fagonia cretica may possess partial agonistic property or the effects of the other mixture components, this was in line with the contradictory effects reported in the traditional use.

Since the experiment was carried out on isolated rabbit jejunum, only two possibilities for the mechanism by which the relaxant effect can occur, either through adrenergic pathway or direct smooth muscle relaxant effects.

The non-selective $\beta$-blocker (Propranalol) shifted the dose-response curve of ethanolic extract of Fagonia cretica linn to the right in dose-dependent fashion similar to that produced by adrenaline, which can be taken as an evidence of the existence of $\beta$-Adrenoceptors activity in mediating the relaxant effect of the extract. The estimated $\mathrm{pA}_{2}$ confirmed the significance of difference $(\mathrm{p}=0.001$ and $\mathrm{p}=0.003$ ) in receptors affinities between the extract and the standard adrenaline in competitive way. Although, the literature revealed that Fagonia cretica was used traditionally to treat bronchial asthma, those findings were scientifically approved.

The famous pharmacological feature of rabbit intestine, the unusual effect in which both $\beta$ and $\alpha$ adrenergic receptor types mediate the smooth muscle relaxation, thus the non-selective $\alpha$-blocker (phentolamine) was used to confirm the presence of the role of $\alpha$ activity that may underlay the extract relaxation, whereas our findings revealed that, phentolamine succeed competitively in shifting the dose- response curves of Fagonia cretica to the right in a dose- 
dependent manner calculated as $\mathrm{pA}_{2}$ value indicating the significant participation of $\alpha$ activity comparable to standard Adrenaline.

The effect of Fagonia cretica on $\alpha$-receptor was in line with the folkloric use of the plant to induce abortion since the uterus smooth muscle enriches with $\alpha 1$-adrenoceptors whose stimulation increases uterus contractility.

On the other hands, Our findings exclude any contribution of the other alternative possible option that postulates the relaxant effect may be mediated through the direct effect of the plant extract on the intestine smooth muscle filaments, these checked by the competitive blockage of the both $\alpha$ and $\beta$-adrenergic receptor types by the relevant standard antagonists within the rabbit small intestine and with comparison with standard adrenaline.

These findings were agreed with the effect of harmine a known monoamine oxidase A and B inhibitors isolated from the plant, that decreases the degradation of monoamine in the gut and increases their relaxation effect on the smooth muscle of the gut.

\section{Conclusion}

The ethanolic extract of Fagonia cretica linn (Zygophyllaceae) exhibited a dose-dependent relaxant activity on rabbit jejunum smooth muscle, mediated through both $\alpha$ and $\beta$ adrenoceptors and with no participation of a direct muscle relaxant effect.

Finally, the study recommended, the use of more selective tissue to confirm the determined mechanism of action. Also advance studies were required to identify and correlate the plant constituents to their specific actions, besides, isolation and purification of these compounds for medicinal use.

Lastly, the toxicity evaluation of the plant's main isolated constituent's triterpenoidal saponins was highly recommended.

\section{References}

[1] El Ghazali GEB, El Tohami MS, El Egami AAB, Abdalla WS, Mohammed MG. 1997. Medicinal plants of the Sudan. In: Medicinal plants of northern Kordofan. Omdurman Islamic University Printing and Publishing House, Omdurman. 1997.

[2] Ministry of health and family welfare, department of ayurveda, yoga \& naturopathy, unani, siddha and homoeopathy, new delhi. 2006. The ayurvedic pharmacopoeia of India, $1^{\text {st }}$ Edition, Volume I.

[3] Beier B-A, J A A Nylander, M W Chase, M Thulin. 2004. Phylogenetic relationships and biogeography of the desert plant genus Fagonia (Zygophyllaceae), inferred by parsimony and Bayesian model averaging. Molecular Phylogenetics and Evolution; 33(1):91-108. DOI:10.1016/j.ympev.2004.05.010.

[4] Kabir Md. Sohel, Kaiser Hamid, Latifa Bulbul, Zubaida Khatun, Md. Zahid Alam, Paritosh Chakma. 2010. Effect of ardhabilva kvatha curnaan ayurvedic formulation on lipid profile after chronic administration. Agriculture and biology journal of North America 1(5): 812-816.

[5] Razi Muhammad Tahir, Muhammad Hassham Hassan Bin Asad, Taous Khan, Muhammad Zabta Chaudhary, Muhammad Tayyab Ansari, Muhammad Anwar Arshad \& Qazi Najamus Saqib. 2011. Antihaemorrhagic potentials of Fagonia cretica against Naja naja karachiensis (blackPakistan cobra) venom, Natural Product Research: Formerly Natural Product Letters, 25:20, 1902-1907, DOI: $10.1080 / 14786419.2010 .490785$.

[6] Meena A. K., M. M. Rao. 2010. Folk herbal medicines used by the Meena community in Rajasthan. Asian Journal of Traditional Medicines 5 (1): 19-31.

[7] Harborne JB (1973). Phytochemical methods. Chapman and Hall Ltd.,London. pp. 49-188. 